\title{
Effect of nutritional immunomodulation and heat stress during the dry period on subsequent performance of cows
}

\author{
Thiago F. Fabris, ${ }^{*}$ Jimena Laporta, ${ }^{*}$ Fabiana N. Corra,† Yazielis M. Torres,‡ David J. Kirk,§ Derek J. McLean,\# \\ J. D. Chapman,\# and Geoffrey E. Dahl ${ }^{* 1}$ \\ *Department of Animal Sciences, University of Florida, Gainesville 32611 \\ †Department of Animal Production, São Paulo State University, Botucatu 18618-000, Brazil \\ $\ddagger$ Recinto Universitario de Mayaguez, Universidad de Puerto Rico, Mayaguez, Puerto Rico \\ §Phibro Animal Health, Quincy, IL 62305 \\ \#Phibro Animal Health, Teaneck, NJ 07666
}

\begin{abstract}
Heat stress in dairy cows during the dry period impairs milk yield in the next lactation. Feeding OmniGen-AF (OG; Phibro Animal Health Corp., Teaneck, $\mathrm{NJ})$ to lactating cows during heat stress may increase dry matter intake (DMI) and lowers respiration rate $(\mathrm{RR})$ and rectal temperature (RT), but the effects in dry cows are not known. We hypothesized that OG supplementation before, during, and after the dry period (approximately $160 \mathrm{~d}$ total) would overcome the effects of heat stress and improve cow performance in the next lactation. Cows were randomly assigned to OG or control (placebo) treatments for the last $60 \mathrm{~d}$ in milk (DIM), based on mature-equivalent milk yield in the previous lactation. Cows were dried off $45 \mathrm{~d}$ before expected calving and randomly assigned to heat stress (HT) or cooling (CL) treatments. Thus, cows received dietary supplementation during late lactation before they were exposed to either CL or HT. After dry-off, treatment groups included heat stress with placebo (HT, only shade, $56 \mathrm{~g} / \mathrm{d}$ of placebo, $\mathrm{n}=17$ ), HT with OG supplementation (HTOG, $56 \mathrm{~g} / \mathrm{d}$ of OG, $\mathrm{n}=19)$, cooling with placebo (CL, shade, fans, and soakers, $56 \mathrm{~g} / \mathrm{d}$ of placebo, $\mathrm{n}=16$ ), and CL with OG supplementation (CLOG, $56 \mathrm{~g} / \mathrm{d}$ of $\mathrm{OG}, \mathrm{n}=11$ ). After parturition, all cows were kept under the same CL system and management, and all cows continued to receive OG or control treatment until 60 DIM. Cooling cows during the dry period reduced afternoon RT (CL vs. $\mathrm{HT} ; 38.9 \pm 0.05$ vs. $39.3 \pm 0.05^{\circ} \mathrm{C}$ ) and RR (CL vs. $\mathrm{HT} ; 45 \pm 1.6$ vs. $77 \pm 1.6$ breaths/min). Respiration rate was also decreased by OG supplementation under HT conditions (HTOG vs. HT; $69.7 \pm 1.6$ vs. $77.2 \pm$ 1.6 breaths/min). An interaction was observed between
\end{abstract}

Received November 15, 2016.

Accepted April 6, 2017.

${ }^{1}$ Corresponding author: gdahl@ufl.edu
OG supplementation and HT; HTOG cows tended to have lower morning RT compared with HT cows. During the dry period, OG reduced DMI relative to control cows. Birth weight was greater in calves from CL cows (CL vs. HT; $40.6 \pm 1.09$ vs. $38.7 \pm 1.09 \mathrm{~kg}$ ). No differences were detected among treatments in hematocrit, total protein, and body condition score. Cows offered CLOG, CL, and HTOG treatments had greater body weight during the dry period $(794.9 \pm 17.9,746.8 \pm$ 16.7 , and $762.9 \pm 14.9 \mathrm{~kg}$, respectively) than HT cows $(720 \pm 16.2 \mathrm{~kg})$. Gestation length was approximately $4 \mathrm{~d}$ longer for CL cows compared with HT cows. Cows offered CLOG, CL, and HTOG treatments produced more milk $(41.3 \pm 1.6,40.7 \pm 1.6$, and $40.5 \pm 1.6 \mathrm{~kg} / \mathrm{d}$, respectively) than HT treatment $(35.9 \pm 1.6 \mathrm{~kg} / \mathrm{d})$. Body weight after parturition and DMI were evaluated up to 60 DIM and averaged $661.5 \pm 15.8$ and 19.4 $\pm 0.7 \mathrm{~kg} / \mathrm{d}$, respectively, with no differences observed among treatments. These results confirm that exposure of dry cows to heat stress negatively affects milk yield in the subsequent lactation. Active cooling of dry cows and OG supplementation can reduce the negative effects of heat stress in the dry period on subsequent performance.

Key words: dairy cow, cooling system, heat stress, dry period, OmniGen-AF

\section{INTRODUCTION}

High temperatures negatively affect the performance of dairy cattle, and high humidity exacerbates this effect (Tao et al., 2011). Mammals possess highly regulated physiological mechanisms to maintain homeostasis when the temperature exceeds the thermoneutral zone (TNZ), which is the range of ambient temperature in which an animal does not have to expend large amounts of energy to control its body temperature. Heat stress occurs when temperatures exceed the animal's TNZ. When ambient temperature exceeds $27^{\circ} \mathrm{C}$, even with 
low humidity, the effective temperature is above the TNZ for high-producing dairy cows (Armstrong, 1994). Animals use physiological and behavioral mechanisms to maintain body temperature in hot and humid climates. Several indexes have been used to estimate the degree of thermal heat stress experienced by dairy cows, such as the temperature-humidity index (THI), which is associated with increased rectal temperature (RT) in heat-stressed cows (Dikmen and Hansen, 2009). Dairy cows experience heat stress when THI is greater than 68 (Zimbelman et al., 2009). Heat stress negatively affects profitability of the US dairy industry (St-Pierre et al., 2003). Specifically, heat stress during the dry period has a negative effect on subsequent milk yield (Tao et al., 2011) and reduces gestation length and calf birth weight (Tao et al., 2012a; reviewed by Tao and Dahl, 2013).

A common management practice for heat stress abatement is through active cooling of cows using fans and soakers. In addition, nutritional management practices, alone or in combination with active cooling, have been proposed to reduce the effect of stress during the dry period. One preliminary report indicate that feeding OmniGen-AF (OG; Phibro Animal Health Corporation, Teaneck, NJ) increased DMI, and reduced respiration rate $(\mathbf{R R})$ and $\mathrm{RT}$ in lactating cows under heat stress (Hall et al., 2014). In addition, feeding OG alone to cows under heat stress decreased RT and RR and increased subsequent yield (Brandão et al., 2016), but the effects of feeding OG along with cooling in dry cows are not known. To date, no studies have been conducted to evaluate the effect of OG supplementation before, during, and after the dry period to cooled and heat-stressed cows.

We hypothesized that OG supplementation before, during, and after the dry period (approximately 160 d) would overcome the negative effects of heat stress during the dry period and improve subsequent performance of dairy cattle. Therefore, the objective of this study was to determine if OG supplementation improves thermoregulation of dairy cows under heat stress conditions during the dry period and whether the supplementation improves cow performance after parturition.

\section{MATERIALS AND METHODS}

\section{Treatments, Experimental Design, and Animals}

The study was conducted during one summer season (2015) at the University of Florida Dairy Unit (Hague, FL). All treatments and procedures were approved by the University of Florida IACUC. A $2 \times 2$ factorial design was used to evaluate the effects of feeding OG upon performance of dairy cattle experiencing heat stress during the dry period. OmniGen-AF contains a mixture of silicon dioxide, calcium aluminosilicate, sodium aluminosilicate, brewer's dehydrated yeast, mineral oil, calcium carbonate, rice hulls, niacin supplement, biotin, calcium D-pantothenate, vitamin $\mathrm{B}_{12}$ supplement, choline chloride, thiamine mononitrate, pyridoxine hydrochloride, riboflavin-5-phosphate. and folic acid, but full formulation is proprietary.

Sixty days before dry-off, cows were randomly assigned to OG or control (placebo) treatments based on mature equivalent milk yield in the previous lactation. Before dry-off, all cows were kept under cooling systems and under normal dairy farm management. Cows that did not receive OG were fed $56 \mathrm{~g} / \mathrm{d}$ of bentonite as a placebo control (AB20, Phibro Animal Health Corp.). Cows were dried off $45 \mathrm{~d}$ before expected calving, and OG treatments continued when both groups were exposed to CL or HT treatment. Average parity did not differ among groups $(2.77 \pm 0.21, P=0.18)$. After dry-off, treatment groups were as follows: heat stress, only shade (HT, n = 17, $56 \mathrm{~g} / \mathrm{d}$ of placebo); HT with OG (HTOG, $56 \mathrm{~g} / \mathrm{d}$ of $\mathrm{OG}, \mathrm{n}=19$ ); cooling with shade, fans, and soakers (CL, $56 \mathrm{~g} / \mathrm{d}$ of placebo $\mathrm{n}=$ 16); and CL with OG (CLOG, $56 \mathrm{~g} / \mathrm{d}$ of OG $\mathrm{n}=11$ ). After parturition, all cows were kept under the same cooling system and management, and they continued receiving OG or control treatment until 60 DIM consistent with dry period treatment. Cows were housed in a sand-bedded free-stall barn during lactation and the dry period. During the dry period, the pen for CL and CLOG cows was equipped with active cooling systems including shade, soakers (Rain Bird Manufacturing, Glendale, CA), and fans (J\&D Manufacturing, Eau Claire, WI), whereas the pen for HT and HTOG cows only received shade. When the ambient temperature exceeded $21.1^{\circ} \mathrm{C}$, fans automatically turned on and the soakers were activated for $1.5 \mathrm{~min}$ at 5 -min intervals. Photoperiod (14 h light/10 h dark) of the barn for dry cows on all treatments was controlled using metal halide lights. The lights provided approximately 250-lx intensity at eye level of cows and were kept on from 0600 to $2000 \mathrm{~h}$. After calving, all cows were housed in the same sand-bedded free-stall barn with shade, soakers, and fans for cooling. The THI was calculated based on the equation reported by Dikmen et al. (2008): THI $=(1.8 \times \mathrm{T}+32)-[(0.55-0.0055 \times \mathrm{RH}) \times(1.8$ $\times \mathrm{T}-26)]$, where $\mathrm{T}=$ air temperature $\left({ }^{\circ} \mathrm{C}\right)$ and $\mathrm{RH}$ $=$ relative humidity (\%). Air temperature and relative humidity of each pen in the barn for dry cows were recorded every 15 min by Hobo Pro series Temp probes (Onset Computer Corp., Pocasset, MA). 


\section{Data Measures and Sample Collection}

Before dry-off (at least $60 \mathrm{~d}$ ) cows were separated into 2 groups as follows: one with OG supplementation and other without OG supplementation. All cows were fed the same diet (late lactation diet, Table 1) throughout this period. All cows were fed a common close-up TMR (Table 1), and cows were still receiving OG or control diets during the entire dry period. The daily DMI of individual cows was measured from dryoff to calving using a Calan gate system (American Calan Inc., Northwood, NH). Body weight and BCS were measured once each week during the dry period. Total daily water intake for each pen (HT and CL) was recorded during the dry period, and individual daily water intake was estimated by dividing water consumption by the number of cows in each pen (L/d). Hydration status of individual cows was monitored by assessing hematocrit (HCT) percentage 3 times a week (1400 h; Monday, Wednesday, and Friday). After collection, blood samples were immediately placed on ice and centrifuged at 2,619 $\times g$ for $20 \mathrm{~min}$ and HCT and total protein (TP) was assessed. Rectal temperature was measured twice daily ( 0730 and $1430 \mathrm{~h}$ ) by using a GLA M700 digital thermometer (GLA Agricultural Electronics, San Luis Obispo, CA), and RR was measured thrice weekly (1400 h; Monday, Wednesday, and Friday) by counting the flank movements for $1 \mathrm{~min}$ for all cows during the entire dry period to confirm the heat stress on cows. After parturition, all cows were managed identically as a single group, and all cows were cooled during lactation. Cows were milked twice a day, and daily milk yield was recorded for the first 9 wk of lactation. Milk components (protein, fat, and lactose) were measured using the AfiLab milk analyzer (Kibbutz Afikim, Israel) at each milking, and SCS was collected and analyzed monthly from DHIA records. The AfiLab milk analyzer is based on the optical characteristics of light scattering of matter such as milk fat, protein, and lactose; and the values obtained using AfiLab are well correlated with DHIA measures (Kaniyamattam and De Vries, 2014). A common diet (Table 1) was fed to all cows after parturition, and DMI was recorded for the initial 60 DIM. All cows were still receiving OG or control diets until 60 DIM.

\section{Statistical Analysis}

Data were analyzed in 2 distinct periods, during the dry period, when treatment with evaporative cooling was provided or not, along with dietary interventions, and during the postpartum period when only dietary treatments were applied. Descriptive statistics were used to describe the daily mean and respective SD for THI.

For the dry period, the responses RT, RR, HCT, TP, $\mathrm{BW}, \mathrm{BCS}$, and DMI were analyzed using the MIXED procedure of SAS version 9.4 (SAS Institute Inc., Cary, NC). The statistical models included the fixed effects dietary treatment (control vs. OG), prepartum evaporative cooling (HT vs. CL), the interaction between dietary treatment and evaporative cooling, week prepartum $(-1,-2,-3,-4,-5,-6,-7)$, the interactions between dietary treatment and week prepartum, evaporative cooling and week prepartum, and among dietary treatment and evaporative cooling and week prepartum, and the random effect of cow nested within dietary treatment and evaporative cooling. During the dry period, the THI to which each cow was exposed was used as a covariate for analyses of RT, RR, and DMI.

For the postpartum period, the responses milk yield, milk composition, BW, SCS, feed efficiency, and DMI were analyzed using the MIXED procedure of SAS. The statistical models included the fixed effects dietary treatment (control vs. OG), prepartum evaporative cooling (HT vs. CL), the interaction between dietary treatment and evaporative cooling, week postpartum $(1,2,3,4,5,6,7,8,9)$, the interactions between dietary treatment and week postpartum, evaporative cooling and week postpartum, and among dietary treatment and evaporative cooling and week postpartum, and the random effect of cow nested within dietary treatment and evaporative cooling.

Data on gestation length and dry period length were analyzed using the MIXED procedure of SAS with statistical models that included the fixed effects dietary treatment (control vs. OG), prepartum evaporative cooling (HT vs. CL), and the interaction between dietary treatment and evaporative cooling. Calf birth weight was analyzed by the MIXED procedure of SAS with a statistical model that included the fixed effects of calf sex (male vs. female), dietary treatment (control vs. OG), prepartum evaporative cooling (HT vs. CL), and the interaction between dietary treatment and evaporative cooling.

Models were fit to the data, and distribution of residuals and homogeneity of variance were evaluated. Data that did not fit the assumptions of normality were transformed before analyses, and LSM and respective SEM were back-transformed for data presentation. The Kenward-Roger method was used to obtain the approximate degrees of freedom. The covariance structure that resulted in the best fit model based on the smallest Akaike's criterion was selected for the analysis of data with repeated measurements. The LSM \pm SEM are reported. Differences with $P \leq 0.10$ were considered 
Table 1. Ingredient composition and nutrient content of late lactation, prepartum, and postpartum diets

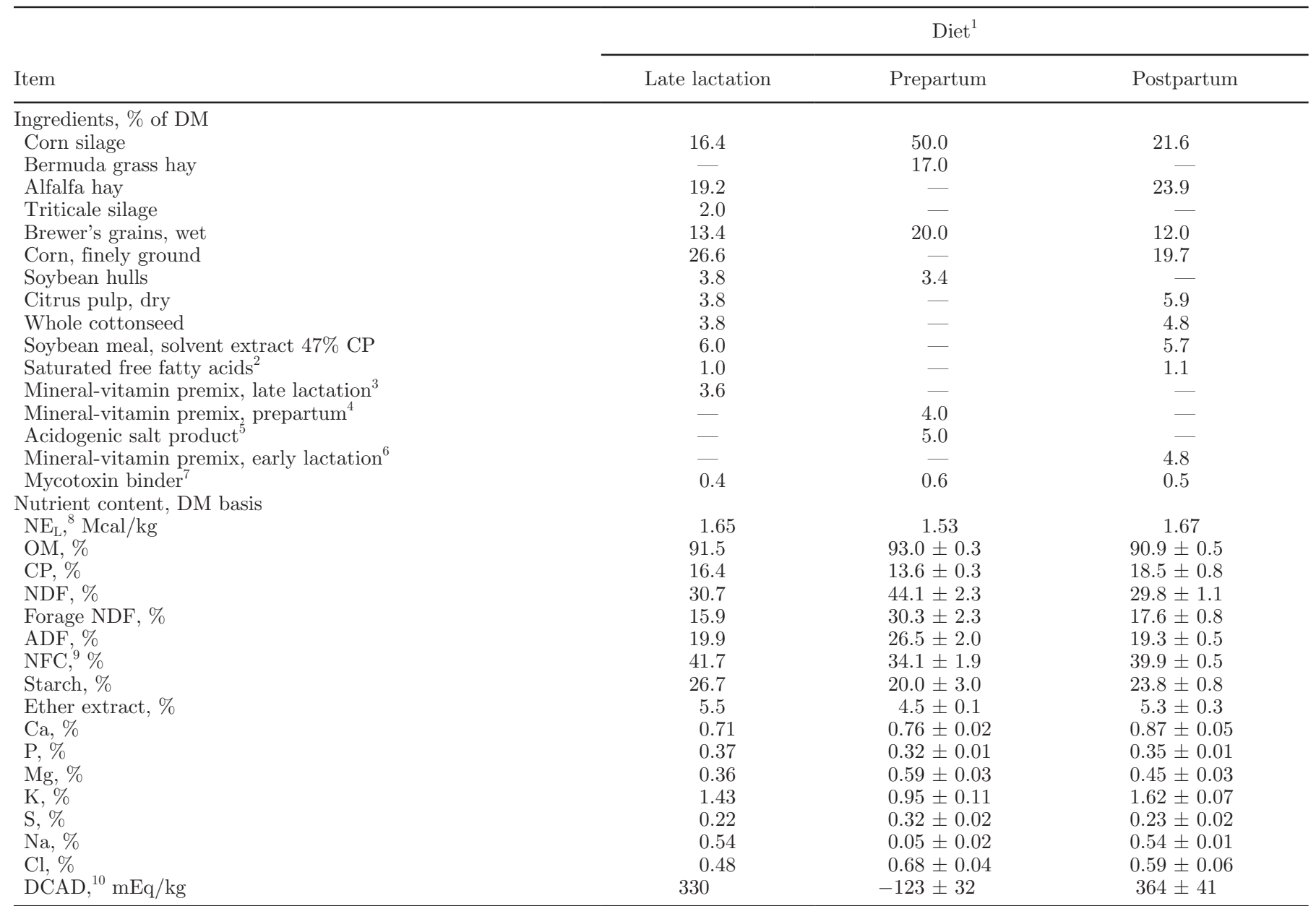

${ }^{1}$ Late gestation diet was fed at least $60 \mathrm{~d}$ before dry-off. Prepartum diet was fed from $231 \mathrm{~d}$ of gestation to calving and postpartum diet from calving to 60 DIM.

${ }^{2}$ Energy Booster Mag; Milk Specialties, Eden Prairie, MN.

${ }^{3}$ The late lactation mineral and vitamin supplement contained (DM basis) $12.4 \%$ ground corn grain, $29.8 \%$ sodium sesquicarbonate, $14.3 \%$ DCAD Plus (Arm and Hammer Animal Nutrition, Trenton, NJ), 13.2\% calcium carbonate, 7.7\% magnesium oxide, $6.6 \%$ sodium chloride, 6.6\% dicalcium phosphate, 0.99\% ClariFly Larvicide (Central Life Sciences, Schaumburg, IL), 0.38\% Sel-Plex 2000 (Alltech Biotechnology, Nicholasville, KY), 0.22\% Intellibond Vital 4 (Micronutrients, Indianapolis, IN), 0.20\% Rumensin 90 (Elanco Animal Health, Greenfield, IN), 0.0017 ethylenediamine dihydriodide, $0.16 \%$ of a premix containing vitamins A, D, and E, and $5.7 \%$ potassium chloride. Each kilogram contains $6.0 \% \mathrm{Ca}, 1.1 \% \mathrm{P}, 3.9 \% \mathrm{Mg}, 10.2 \% \mathrm{~K}, 0.13 \% \mathrm{~S}, 9.7 \% \mathrm{Na}, 7.2 \% \mathrm{Cl}, 520 \mathrm{mg}$ of Zn, $120 \mathrm{mg}$ of Cu, $430 \mathrm{mg}$ of $\mathrm{Mn}, 7 \mathrm{mg}$ of Se, $3.6 \mathrm{mg}$ of Co, $12 \mathrm{mg}$ of I, 160,000 IU of vitamin A, 28,000 IU of vitamin D, $750 \mathrm{IU}$ of vitamin E, and $400 \mathrm{mg}$ of monensin.

${ }^{4}$ The prepartum mineral and vitamin supplement contained (DM basis) $64.1 \%$ corn gluten feed, $8.2 \%$ calcium carbonate, $15.7 \%$ magnesium sulfate heptahydrate, $6.0 \%$ magnesium oxide, $2.3 \%$ sodium chloride, $0.42 \%$ Sel-Plex 2000 (Alltech Biotechnology), $0.27 \%$ Intellibond Vital 4 (Micronutrients), $0.002 \%$ ethylenediamine dihydriodide, $0.66 \%$ of a premix containing vitamins A, D, and E, $0.37 \%$ Rumensin 90 (Elanco Animal Health), and 2.0\% ClariFly Larvicide (Central Life Sciences). Each kilogram contained 13.6\% CP, 3.7\% Ca, 0.7\% P, 5.5\% Mg, 0.9\% K, 1.1\% $\mathrm{Na}, 1.6 \% \mathrm{Cl}, 2.6 \% \mathrm{~S}, 788 \mathrm{mg}$ of Zn, $180 \mathrm{mg}$ of Cu, $581 \mathrm{mg}$ of Mn, $9 \mathrm{mg}$ of Se, $4.4 \mathrm{mg}$ of Co, $16 \mathrm{mg}$ of I, 104,000 IU of vitamin A, $30,000 \mathrm{IU}$ of vitamin $\mathrm{D}, 1,500 \mathrm{IU}$ of vitamin $\mathrm{E}$, and $800 \mathrm{mg}$ of monensin.

${ }^{5}$ SoyChlor, West Central Soy, Landus Cooperative, Ames, IA.

${ }^{6}$ The early lactation mineral and vitamin supplement contained (DM basis) 19.4\% LysAAmet blood meal (Perdue Agribusiness, Salisbury, MD), 26.8\% sodium sesquicarbonate, 14.4\% DCAD Plus (Arm and Hammer Animal Nutrition), 5.7\% potassium chloride, 13.2\% calcium carbonate, 4.0\% dicalcium phosphate, $7.7 \%$ magnesium oxide, $6.6 \%$ sodium chloride, $0.22 \%$ Intellibond Vital 4 (Micronutrients), $0.39 \%$ Sel-Plex 2000 (Alltech Biotechnology), $0.0015 \%$ ethylenediamine dihydriodide, $0.32 \%$ of a premix containing vitamins A, D, and $\mathrm{E}, 0.11 \%$ biotin $2 \%, 0.22 \%$ Rumensin 90 (Elanco Animal Health), and 1.0\% ClariFly Larvicide (Central Life Sciences). Each kilogram contains 17.2\% CP, 6.2\% Ca, 0.9\% $\mathrm{P}, 4.5 \% \mathrm{Mg}, 10.4 \% \mathrm{~K}, 11.5 \% \mathrm{Na}, 7.2 \% \mathrm{Cl}, 0.2 \% \mathrm{~S}, 605 \mathrm{mg}$ of $\mathrm{Zn}, 143 \mathrm{mg}$ of Cu, $490 \mathrm{mg}$ of Mn, $8 \mathrm{mg}$ of Se, $4.4 \mathrm{mg}$ of Co, $12 \mathrm{mg}$ of I, 160,000 IU of vitamin A, 28,000 IU of vitamin D, 1,500 IU of vitamin E, and $460 \mathrm{mg}$ of monensin.

${ }^{7}$ NovaSilPlus, BASF, Florham Park, NJ.

${ }^{8}$ Calculated using the NRC (2001) according to the chemical composition of the dietary ingredients and adjusted for 21 , 11 , and $20 \mathrm{~kg}$ of DM intake for the late gestation, pre- and postpartum periods, respectively.

${ }^{9}$ Calculated as follows: NFC $=\mathrm{DM}-($ ash $+\mathrm{CP}+$ ether extract $+\mathrm{NDF}-\mathrm{NDF}$ insoluble CP $)$.

${ }^{10}$ Calculated as follows: $\mathrm{DCAD}=[(\mathrm{mEq}$ of $\mathrm{K})+(\mathrm{mEq}$ of $\mathrm{Na})]-[(\mathrm{mEq}$ of $\mathrm{Cl})+(\mathrm{mEq}$ of $\mathrm{S})]$. 
statically significant and between $0.10 \leq P \leq 0.15$ was referenced as a tendency.

\section{RESULTS}

\section{Measurements During Dry Period}

Pens for HT and CL cows had similar THI (Figure 1) during the dry period, which was expected, because the cooling system in the current experiment was designed to cool the animals and not the environment. During the dry period, the average THI (THI/h) was measured from June 4 to October 10, 2015, and the THI was never lower than 68 at any time of the day or night (Figure 1, inset). Cooling cows during the dry period reduced morning RT (CL vs. HT, $P<0.01$; Table 2; Figure 2), afternoon RT (CL vs. HT, $P<$ 0.01 ; Table 2), and RR (CL vs. HT, $P<0.01$; Table 2; Figure 2). Supplementation with OG also decreased RR (OG vs. non-OG, $P<0.01$; Table 2). An interaction existed between OG supplementation and HT for RR $(P=0.07$; Table 2$)$; HTOG cows tended to have lower morning RT compared with HT cows $\left(-0.065^{\circ} \mathrm{C}\right.$, Table 2, Figure 2). During the dry period, HT and OG supplementation reduced DMI relative to cooled and non-OG fed cows (Table 2; $P=0.10$ and $P=0.07$, respectively). Calf birth weight was greater in calves from CL cows relative to HT cows (Table 2; $P=0.02$ ). No differences in HCT, TP (Table 3), or BCS (Table 2) were detected among treatments. As a group, HT cows consumed more water than CL cows (41.40 vs. 21.5 L/d). During the dry period, BW was measured daily to produce a weekly mean value for further analysis. Cooling treatment had higher BW compared with HT treatment $(P=0.08)$, and $\mathrm{OG}$ supplementation also increased BW compared with cows that did not receive

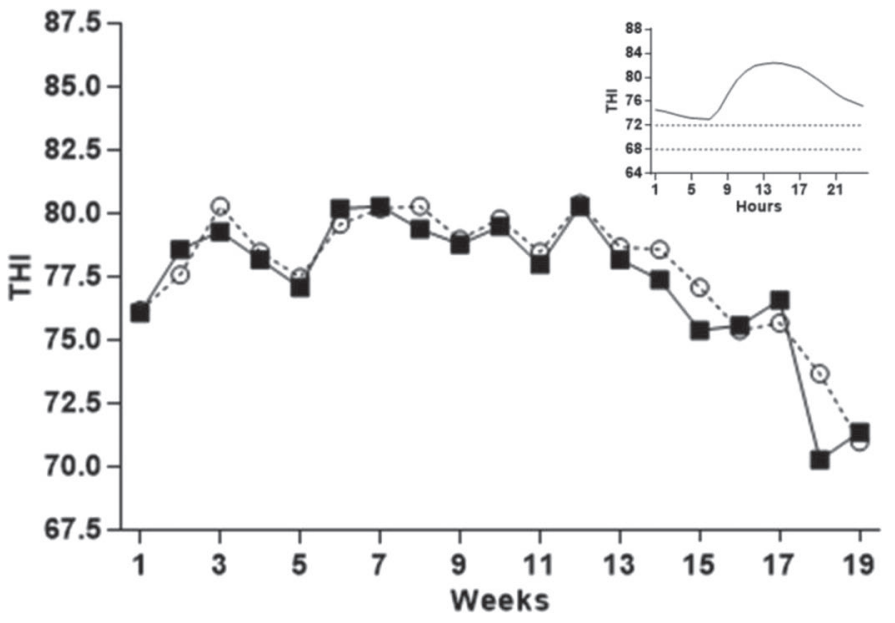

Figure 1. Average temperature-humidity index (THI) during the dry period of cooled and heat stress (HT) treatment pens. Open circles $(\bigcirc)$ and solid squares (ם) represent cooled and shade only pens, respectively. The inset represents the average THI in hours of the day during the entire period. Dashed lines represent the threshold when cows start to experience the effect of HT, and the solid line represents the daily average THI per hour.

OG supplementation (Table 2; $P<0.01$ ). Gestation length was $3.8 \pm 2.0 \mathrm{~d}$ longer for CL cows compared with HT cows $(P=0.01$, Table 2$)$, but no treatment effect was observed with OG supplementation $(1.5 \pm 1.9$; $P=0.30$, Table 2) compared with nonsupplemented cows. Similarly, dry period length was reduced by HT regardless of OG treatment $(P=0.01$, Table 2$)$.

\section{Production Variables During Lactation}

Cows exposed to HT during the dry period had decreased milk yield compared with cows provided with active CL, regardless of OG treatment $(P<0.09$; Fig-

Table 2. Temperature-humidity index (THI) of the pens, dry period length (DPL), gestation length (GL), rectal temperature (RT), respiration rate $(\mathrm{RR}), \mathrm{BW}$, and calf birth weight (CBW) of cooled or heat-stressed cows during the dry period and receiving OmniGen-AF (OG; Phibro Animal Health Corp., Teaneck, NJ) or placebo control from $60 \mathrm{~d}$ before dry period to $60 \mathrm{~d}$ after calving (total of $160 \mathrm{~d}$ )

\begin{tabular}{|c|c|c|c|c|c|c|c|c|}
\hline Variable & \multicolumn{4}{|c|}{ Treatment $^{1}$} & SEM & \multicolumn{3}{|c|}{$P$-value } \\
\hline Pen THI & 77.6 & 77.90 & - & - & - & - & - & - \\
\hline $\mathrm{GL}, \mathrm{d}$ & 278.2 & 274.4 & 279.6 & 276 & 1.43 & 0.01 & 0.30 & 0.97 \\
\hline $\mathrm{RT}$ day, ${ }^{\circ} \mathrm{C}$ & $38.59^{\mathrm{a}}$ & $38.84^{\mathrm{c}}$ & $38.69^{\mathrm{b}}$ & $38.77^{\mathrm{bc}}$ & 0.04 & $<0.01$ & 0.56 & 0.02 \\
\hline $\mathrm{RT}$ night, ${ }^{\circ} \mathrm{C}$ & 38.92 & 39.31 & 39.00 & 39.28 & 0.05 & $<0.01$ & 0.62 & 0.25 \\
\hline $\mathrm{BCS}$ & 3.5 & 3.41 & 3.41 & 3.55 & 0.08 & 0.79 & 0.74 & 0.15 \\
\hline CBW, kg & 40.6 & 38.7 & 43.1 & 39.7 & 1.09 & 0.02 & 0.11 & 0.48 \\
\hline DMI, $\mathrm{kg} / \mathrm{d}$ & 11.0 & 10.3 & 10.2 & 9.3 & 0.46 & 0.10 & 0.07 & 0.90 \\
\hline
\end{tabular}

\footnotetext{
${ }_{\mathrm{a}-\mathrm{c}}$ Means differ significantly (a vs. b, b vs. c; $P<0.05$; a vs. c, $P<0.01$ ).

${ }^{1}$ Treatment included cooling $(\mathrm{CL} ; \mathrm{n}=15)$, heat stress $(\mathrm{HT} ; \mathrm{n}=16)$, CL with OG (CLOG; $\left.\mathrm{n}=14\right)$, and HT with OG $($ HTOG; $\mathrm{n}=19)$.
}

${ }^{2}$ During the dry period, BW was collected weekly and averaged for the statistical analysis (7 wk before calving). 

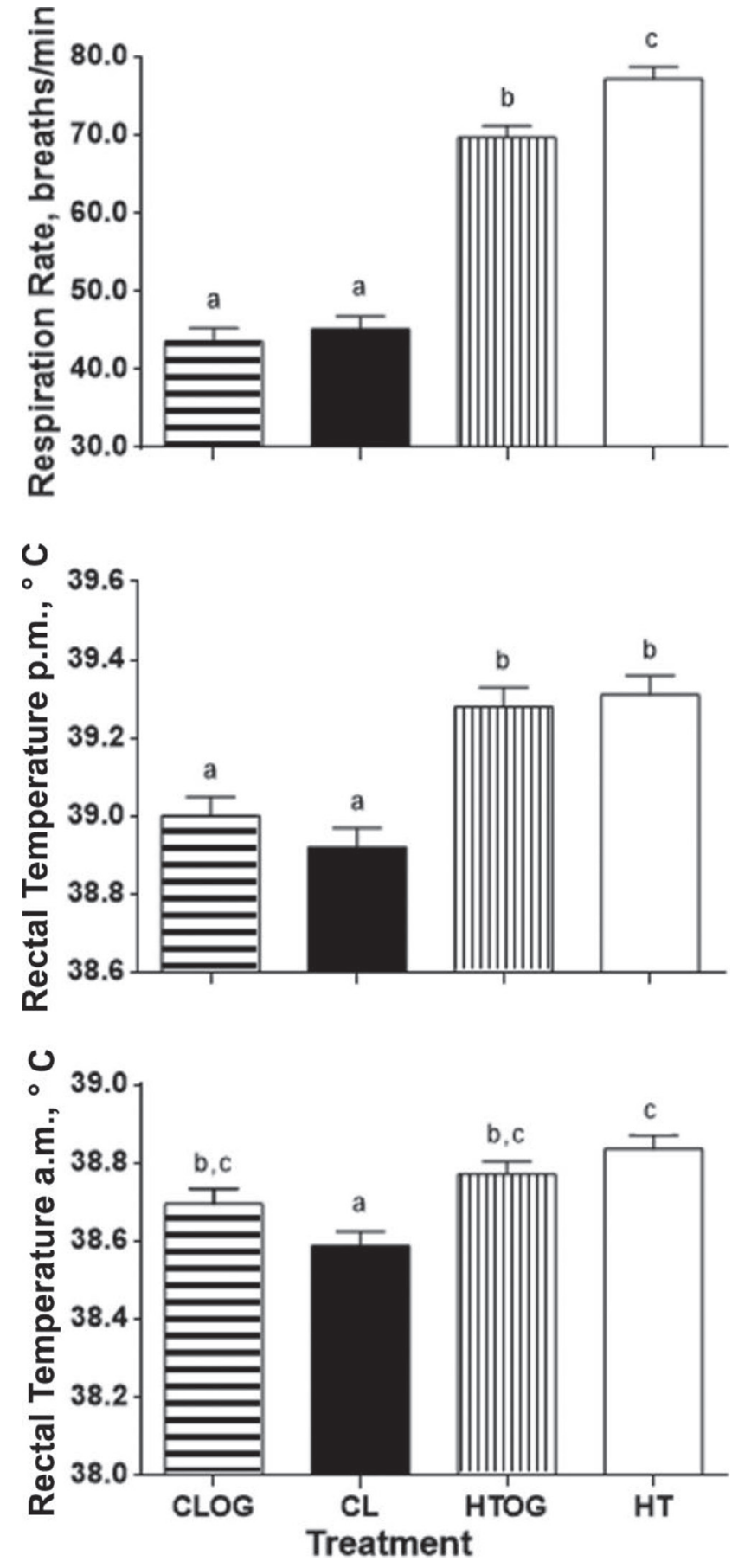

Figure 2. Effect of prepartum evaporative cooling and dietary treatment (fed $56 \mathrm{~g} / \mathrm{d}$ of AB20, control; or fed $56 \mathrm{~g} / \mathrm{d}$ of OmniGenAF, OG; both products from Phibro Animal Health Corp., Teaneck, $\mathrm{NJ})$ before and during the dry period on respiration rate $(\mathrm{RR})$ and rectal temperature (RT). Effect of cooling (CL; $\mathrm{n}=15)$, heat stress $(\mathrm{HT} ; \mathrm{n}=16)$, CL with OG (CLOG; $\mathrm{n}=14)$, or HT with OG (HTOG; $\mathrm{n}=19$ ) during a 45-d dry period on morning and afternoon RT (SEM $=0.04$ and $\mathrm{SEM}=0.05$, respectively $)$ and $\mathrm{RR}(\mathrm{SEM}=1.59)$. During the prepartum period, CL systems reduced morning and afternoon RT and RR $(P<0.01)$; HTOG cows tended to have lower morning RT compared with HT cows $\left(-0.065^{\circ} \mathrm{C}\right)$. Means with different letters differ significantly (a vs. b, b vs. c; $P<0.05$; a vs. c, $P<0.01$ ). Error bars represent pooled SEM. ure 3). Until 9 wk postpartum, CL cows produced (40.7 $\pm 1.6 \mathrm{~kg} / \mathrm{d})$ more milk relative to HT cows $(35.9 \pm$ $1.6 \mathrm{~kg} / \mathrm{d}$ ). No treatment effects on milk fat, protein, or lactose concentrations or on SCS were observed during lactation. Milk yield did not differ when OG was fed to cooled cows (CL vs. CLOG, $P<0.81$ ). However, a significant difference in milk yield occurred when HT cows were supplemented with OG compared with HT cows (HTOG vs. HT, $40.5 \pm 1.6$ vs. $35.9 \pm 1.6 \mathrm{~kg} / \mathrm{d}, P$ $<0.03$ ). During the postpartum period, DMI (Figure 4) and BW did not differ among treatments (Table 4).

\section{DISCUSSION}

Dry cows suffer several negative outcomes during heat stress and in the subsequent lactation (reviewed by Tao and Dahl, 2013). For example, RT and RR increase with heat stress (Tao et al., 2012b; Wohlgemuth et al., 2016), whereas DMI is lower relative to dry cows that are actively cooled (Tao et. al., 2011). Heat stress also negatively alters immune status of dry cows as evidenced by decreased lymphocyte proliferation and lower antibody production to a nonspecific antigen (do Amaral et al., 2011). Further, heat stress has residual negative effects on immune status in the next lactation including neutrophil oxidative burst activity and phagocytosis (do Amaral et al., 2011). Dry cows that experience HT also produce less milk in the subsequent lactation due to lower mammary cell proliferation during the prepartum period (Tao et al., 2011). Thus, active cooling is one management approach to avoid these effects of HT in dry cows. However, feed-based options may be available to alter the physiological responses observed with hyperthermia, including OG supplementation.

The average THI during the entire study remained above 68 during day and night (Figure 1), and because cows are exposed to heat stress conditions when THI is greater than 68 (Zimbelman et al., 2009), our treatment conditions induced heat stress in the absence of cooling. Further, the CL system was effective to overcome the effect of HT on cooled cows compared with heat-stressed cows as demonstrated by a $0.4^{\circ} \mathrm{C}$ reduction in afternoon $\mathrm{RT}$ (Table 2) and a 32 breaths/min reduction in $\mathrm{RR}$ (Figure 2). Those responses are similar to previous reports that cooled cows had decreased afternoon RT and RR (Tao et al., 2012b). Previous studies indicate that Holstein heifers supplemented with OG had a lower RR compared with heifers without supplementation (Hall et al., 2014). In the same pattern reported here, OG supplementation to HT cows reduced RR compared with only HT cows.

In addition to the effect on RR and RT, HT cows had higher consumption of water relative to CL cows (41.5 
Table 3. Hematocrit and blood total protein of cooled or heat-stressed cows during the dry period ( $\sim 45$ d) and receiving OmniGen-AF (OG; Phibro Animal Health Corp., Teaneck, NJ) or not for $60 \mathrm{~d}$ before, during, and after the dry period

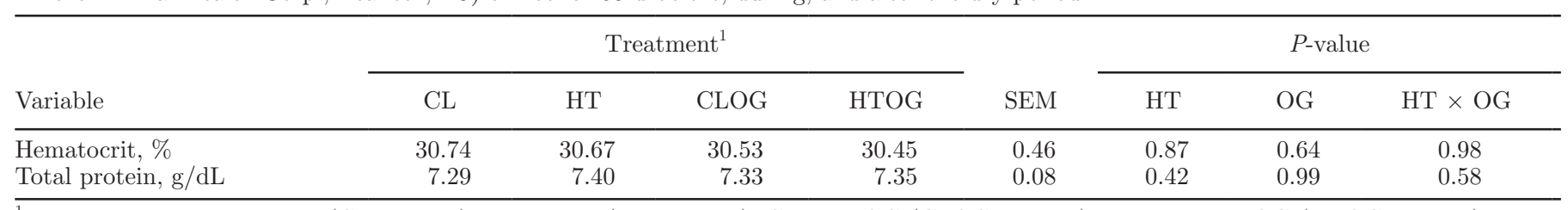

${ }^{1}$ Treatment included cooling $(\mathrm{CL} ; \mathrm{n}=15)$, heat stress (HT; $\left.\mathrm{n}=16\right)$, CL with OG (CLOG; $\left.\mathrm{n}=14\right)$, and HT with OG (HTOG; $\left.\mathrm{n}=19\right)$

vs. $21.5 \mathrm{~L} / \mathrm{d}$ ), which is consistent with previous studies (Tao et al., 2011). Therefore, the HT treatment in the present study was appropriate to evaluate the hypothesis that OG supplementation before, during, and after the dry period (approximately $160 \mathrm{~d}$ ) would overcome the effects of HT and improve cow performance.

Heat stress for long periods influences the thermoregulatory responses of animals and reduces animal productivity (Renaudeau et al., 2012). Animals accumulate heat throughout the day in response to environmental heat and failure to dissipate the heat increment of metabolism and digestion (Beede and Collier, 1986). However, animals that were exposed to CL, CLOG, and HTOG were capable of dissipating more heat to the environment and maintaining body temperature

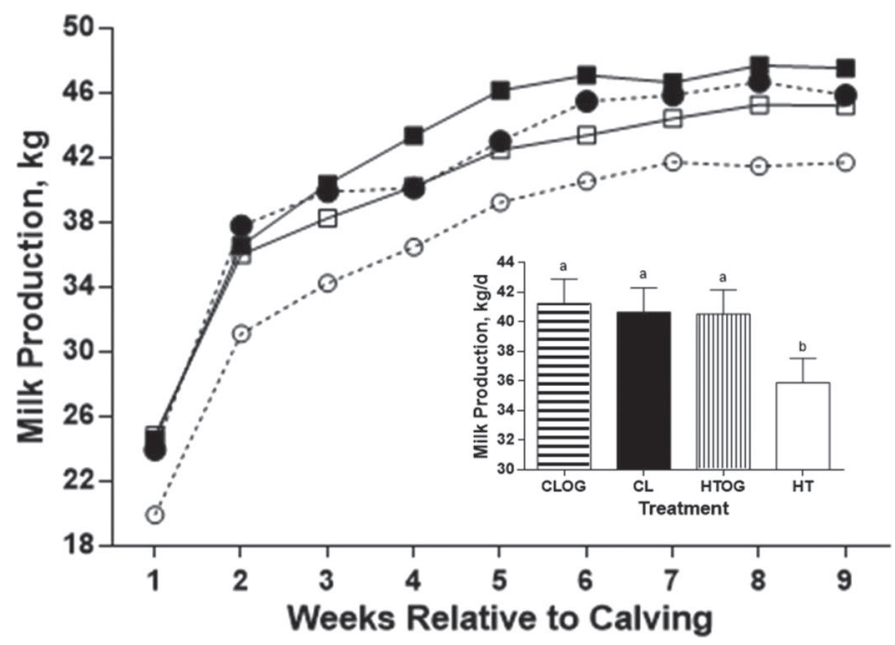

Figure 3. Effect of prepartum evaporative cooling and dietary treatment (fed $56 \mathrm{~g} / \mathrm{d}$ of AB20, control; or fed $56 \mathrm{~g} / \mathrm{d}$ of OmniGenAF, OG; both products from Phibro Animal Health Corp., Teaneck, NJ) before, during, and after the dry period on subsequent milk yield of dairy cows. Effect of cooling (CL; $\mathrm{n}=15)$, heat stress $(\mathrm{HT} ; \mathrm{n}=16)$, CL with OG (CLOG; $\mathrm{n}=14)$, or HT with OG (HTOG; $\mathrm{n}=19)$ during the dry period on milk yield up to 9 wk postpartum. Open circles $(\bigcirc)$ and squares $(\square)$ represent heat-stressed cows and cooled cows, respectively. Solid circles $(\bullet)$ and squares $(\boldsymbol{\square})$ represent supplemented (OG) heat-stressed and cooled cows, respectively. After calving, all cows were managed and housed under same conditions. Main effect of HT $(P=0.09)$, main effect of OG $(P=0.10)$, and main effect of interactions $(P=0.24)$; SEM $=1.62$. The inset represents the average milk yield per group for $60 \mathrm{~d}$. Different letters $(\mathrm{a}, \mathrm{b})$ represent significant differences between groups $(P<0.05)$. Error bars represent pooled SEM. at lower levels compared with HT treatment. Those observations indicate that our treatments (evaporative cooling and dietary supplementation) may overcome some of the negative effect of HT, which was also discussed by Beede and Collier (1986), who reported that environmental modification and nutritional management may be applied to overcome the negative effect of heat stress.

The reduction of the negative effects of heat stress on dairy cow performance can be achieved through application of cooling systems, including shade, evaporative cooling, ventilation, and the combination of these

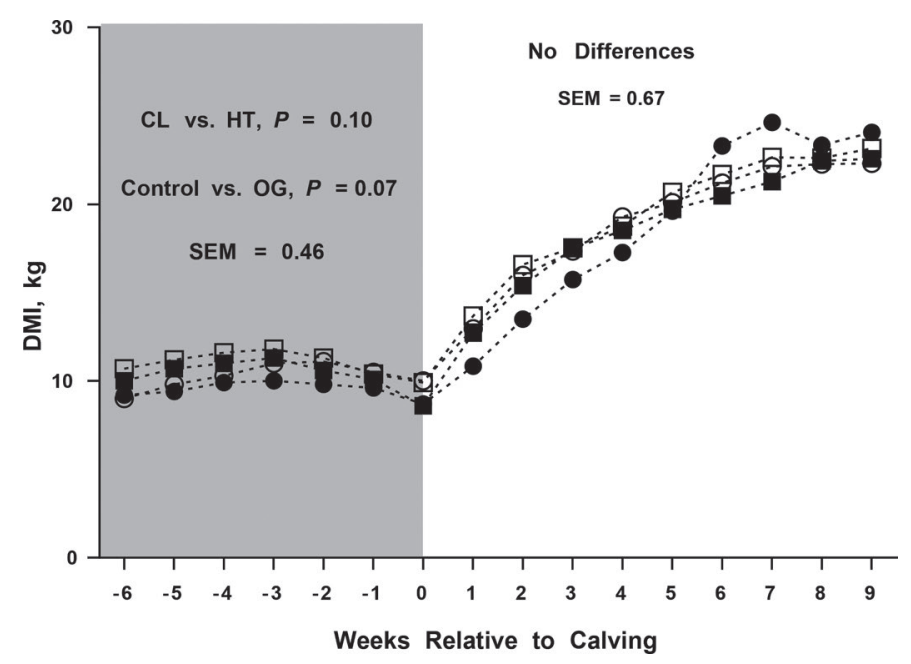

Figure 4. Effect of prepartum evaporative cooling and dietary treatment (fed $56 \mathrm{~g} / \mathrm{d}$ of AB20, control; or fed $56 \mathrm{~g} / \mathrm{d}$ of OmniGenAF, OG; both products from Phibro Animal Health Corp., Teaneck, NJ) before, during, and after the dry period on DMI. Effect of cooling $(\mathrm{CL} ; \mathrm{n}=15)$, heat stress (HT; $\mathrm{n}=16)$, CL with OG (CLOG; $\mathrm{n}=14$ ), or HT with OG (HTOG; $\mathrm{n}=19)$ during the dry period on DMI from -7 to 9 wk relative to calving. Open circles $(\bigcirc)$ and squares $(\square)$ represent heat-stressed cows and cooled cows, respectively. Solid circles $(\boldsymbol{)})$ and squares ( $)$ represent supplemented (OG) heat-stressed and cooled cows, respectively. Data were split into prepartum and postpartum periods and analyzed separately. During the prepartum period, HT and OG supplementation reduced DMI. Main effect of prepartum evaporative cooling (HT vs. CL, $P=0.10$ ), main effect of dietary treatment (control vs. OG, $P=0.07$ ), and main effect of interactions $(P=0.90)$. During the postpartum period, no differences in DMI were observed among treatments. Shade represents the prepartum period. The pooled SEM was 0.46 for the prepartum period and 0.67 for the postpartum period. 
Table 4. Dry matter intake, milk yield, milk composition, BW, and feed efficiency of cooled or heat-stressed cows during the dry period and receiving OmniGen-AF (OG; Phibro Animal Health Corp., Teaneck, NJ) or not throughout the dry period and early in lactation

\begin{tabular}{|c|c|c|c|c|c|c|c|c|}
\hline \multirow[b]{2}{*}{ Variable } & \multicolumn{4}{|c|}{ Treatment $^{1}$} & \multirow[b]{2}{*}{ SEM } & \multicolumn{3}{|c|}{$P$-value } \\
\hline & CL & $\mathrm{HT}$ & CLOG & HTOG & & HT & OG & $\mathrm{HT} \times \mathrm{OG}$ \\
\hline Milk yield, $\mathrm{kg} / \mathrm{d}$ & 40.7 & 35.9 & 41.3 & 40.5 & 1.62 & 0.09 & 0.10 & 0.24 \\
\hline Fat, $\%$ & 3.55 & 3.71 & 3.73 & 3.63 & 0.07 & 0.66 & 0.48 & 0.09 \\
\hline Protein, \% & 2.85 & 2.89 & 2.89 & 2.83 & 0.03 & 0.68 & 0.62 & 0.13 \\
\hline Lactose, $\%$ & 4.70 & 4.63 & 4.70 & 4.65 & 0.02 & 0.01 & 0.61 & 0.82 \\
\hline Lactose yield, $\mathrm{kg} / \mathrm{d}$ & 1.93 & 1.72 & 2.03 & 1.90 & 0.09 & 0.07 & 0.13 & 0.68 \\
\hline SCS & 3.26 & 2.68 & 3.78 & 3.36 & 0.50 & 0.32 & 0.24 & 0.87 \\
\hline $\mathrm{BW},{ }^{2} \mathrm{~kg}$ & 654.8 & 650.2 & 670.3 & 670.9 & 15.75 & 0.89 & 0.26 & 0.87 \\
\hline Feed efficiency ${ }^{3}$ & 2.13 & 1.98 & 2.32 & 2.15 & 0.1 & 0.11 & 0.08 & 0.90 \\
\hline
\end{tabular}

${ }^{1}$ Treatments included cooling $(\mathrm{CL} ; \mathrm{n}=15)$, heat stress (HT; $\left.\mathrm{n}=16\right)$, CL with OG (CLOG; $\left.\mathrm{n}=14\right)$, and HT with OG (HTOG; $\left.\mathrm{n}=19\right)$.

${ }^{2}$ After calving, BW was collected weekly and averaged for the statistical analysis (9 wk into lactation).

${ }^{3}$ Feed efficiency $=\mathrm{kg}$ of $3.5 \%$ FCM per kg of DMI. Feed efficiency was calculated from calving until $60 \mathrm{~d}$ postpartum.

systems (Armstrong, 1994). Effective cooling systems, such as soakers and fans, are needed to wet the cow's hair coat to the skin and to create air movement over the cow's body, thus improving evaporative cooling at the skin level and thereby increasing heat loss to the environment (Collier et al., 2006; Renaudeau et al., 2012). This process is the reason that CL cows had reduced $\mathrm{RT}$ and $\mathrm{RR}$ relative to HT cows. However, the mechanism by which OG supplementation improves thermoregulation and reduces RT and RR is still unknown, and further studies are necessary to determine that mechanism.

During the dry period, HT decreases DMI in cows compared with CL cows (do Amaral et al., 2009; Tao et al., 2011). Following the same pattern in our study, CL cows had higher DMI than HT cows $(P<0.10)$, whereas OG supplementation decreased DMI during the dry period $(P<0.07)$. At parturition, CL cows had higher BW relative to HT cows (Table 2). Decreased BW of HT cows may reflect the high energy demand to maintain body temperature in HT cows, and it may also be associated with the differences in DMI during the dry period. Previous studies have reported lower DMI and BW gain during the dry period under HT (do Amaral et al., 2009; Tao et al., 2011). The difference in BW may be partially explained by greater fetal growth in cows exposed to CL systems and OG supplementation.

Following parturition, nutrient demands increase to initiate and sustain lactation. The effect of heat stress on the balance of nutrient utilization and milk yield is complex. Indeed, after parturition and consistent with higher nutrient demand to sustain a higher level of milk yield after the peak of lactation, one study demonstrated that CL cows had higher DMI at $6 \mathrm{wk}$ postpartum compared with HT cows (Tao et al., 2011).
However, the present study found no difference in postpartum DMI, which is consistent with several other reports and likely reflects the relatively brief duration of intake recording in those studies (do Amaral et al., 2009; Tao et al., 2011). That is, the increase in milk yield precedes the increase in DMI, and because DMI was only measured for $9 \mathrm{wk}$, any potential separation of DMI according to milk had not yet become apparent.

Previous studies indicate that heat stress during the dry period reduces gestation length compared with CL cows (Tao et al., 2012a; reviewed by Tao and Dahl, 2013). In ewes and cows, newborns from dams that were heat stressed during late gestation had decreased birth weight relative to those born to CL dams (Brown et al., 1977; Collier et al., 1982; Tao et al., 2011). The observed reduction in birth weight might be explained by the decreased gestation length and dry period length measured in the present study. Omnigen-AF-supplemented HT cows tended to have longer gestation length and dry period length compared with nonsupplemented HT cows. Cooled cows had calves with higher BW at birth relative to HT cows and OG supplementation tended to increase calf birth weight compared with nonsupplemented cows $(P=0.02$ and $P<0.11$, respectively). These data are consistent with the longer gestation length of cooled and supplemented cows.

Heat stress during the dry period is known to decrease milk yield in the next lactation (Tao et. al., 2011; West, 2003), which is consistent with our results (40.7 vs. $35.9 \mathrm{~kg} / \mathrm{d}$, CL and HT treatments, respectively; Table 4). Similar to the present study, Adin et al. (2009) did not observe differences between CL cows and HT cows in milk fat yield, whereas others have observed greater milk fat yield in CL cows compared with HT cows (Avendaño-Reyes et al., 2006; do Amaral et al., 2009; Tao et al., 2011). Milk protein yield was significantly 
greater for CL cows compared with HT cows, which is consistent with previous studies (Adin et al., 2009; do Amaral et al., 2009, 2011). Higher milk protein yield measured in the present study resulted from the higher milk yield of CL cows because no difference in protein percentage occurred among groups.

OmniGen-AF supplementation of heat-stressed dry cows during late lactation, the dry period, and through 60 DIM increased milk yield in the subsequent lactation compared with heat-stressed dry cows (40.5 vs. 35.9 $\mathrm{kg} / \mathrm{d}$, HTOG and HT treatments, respectively; Table 4, Figure 3), although supplementation of OG to CL cows was without effect. OmniGen-AF supplementation also increased milk fat yield relative to HT cows without supplementation, which reflects the higher milk yield of supplemented HT cows and similar trends were observed for milk protein and lactose yields. It has been reported that OG supplementation during the transition phase resulted in greater milk yield relative to cows that did not receive OG supplementation (Brandão et al., 2016), although the magnitude of the increase was less than that observed in the present study. Similar to the report by Brandão et al. (2016), we did not measure a difference in SCS among treatments. Collectively, the present study extends previous work and suggests that supplementation with OG before, during, and after the entire dry period improves lactation performance in cows exposed to HT.

Compromised mammary growth with HT during the dry period may originate from impaired mammary involution during the early dry period (Tao et al., 2011; Wohlgemuth et al., 2016). In the beginning of the dry period, mammary gland involution is driven by autophagy and apoptosis (Wilde et al., 1997; Sorensen et al., 2006). Apoptosis and autophagy are mechanisms responsible for the elimination and recycling of cells, respectively, and are important for the renewal of mammary cells during the early dry period and cell proliferation during late dry period (Zarzyńska et al., 2007; Sobolewska et al., 2009). At the same time, the renewal process of the mammary gland causes accumulation of a large amount of cellular debris (Capuco et al., 2003), which has to be cleared from the mammary gland by immune cells, such as macrophages and neutrophils, to establish full involution and subsequent mammary development. Therefore, decreased immune activity may slow mammary gland involution in the early dry period and consequently lead to lower cell proliferation during the late dry period, and thus explain the lower milk yield observed with dry period HT. Immunomodulation through a dietary supplement early in the dry period may reverse some of the negative effect of heat stress on immune function.
The lactation curve is a function of mammary epithelial cell number and secretory capacity per cell, and mammary cell number is a function of the difference between cell proliferation and apoptosis (Capuco et al., 2003). The lower milk yield of heat-stressed cows may be due to impaired mammary growth during the dry period (Capuco et al., 2003), and indeed Tao et al. (2011) reported that HT decreases the proliferation of mammary epithelial cells compared with cooled cows, supporting the idea that increased mammary growth supports the higher milk yield observed in CL cows.

Effects of OG supplementation on milk yield may be related to the effect of $\mathrm{OG}$ on immune function, particularly in the early dry period. Heat stress increases the expression of heat shock proteins that have an antiapoptotic effect (Seigneuric et al., 2011) and thus may impair mammary gland involution and negatively affect subsequent milk yield. Further, HT impedes these cellular processes by compromising the cow's immune function, such as impaired chemotaxis and phagocytosis. OmniGen-AF is an immunomodulatory supplement (Wang et al., 2007; Nace et al., 2014), and recent studies have shown that OG feeding improves immune status of heat-stressed dairy cattle (Hall et al., 2014; Brandão et al., 2016). Thus, in the present study, OG feeding before the HT was imposed in the dry period may have improved immune function and allowed for accelerated mammary involution relative to HT alone, but further analysis is needed to evaluate the effect of OG supplementation on immune status during the dry period. This mechanism would also be consistent with the lack of additional effect of $\mathrm{OG}$ in cooled cows. However, further investigation is needed to confirm any effect of OG supplementation on mammary gland development in the early dry period.

\section{CONCLUSIONS}

Heat stress during the dry period negatively affects the performance of dairy cows in the next lactation; that is, heat-stressed cows produce less milk compared with cooled cows. Compared with only heat-stressed cows, OG supplementation in combination with cooling systems improves milk yield. Heat stress negatively affects thermoregulation of dry cows, by increasing RT and RR, and cooling systems and OG supplementation partially reverse that response. Cooling cows and OG supplementation increases gestation length and calf birth weight. However, cooling dry cows improves performance, and OG supplementation may be implemented in association with cooling systems to overcome the negative effects of heat stress during the dry period. 


\section{ACKNOWLEDGMENTS}

The authors thank the staff of the Dairy Unit of University of Florida for animal care and data collection.

\section{REFERENCES}

Adin, G., A. Gelman, R. Solomon, I. Flamenbaum, M. Nikbachat, E Yosef, A. Zenou, A. Shamay, Y. Feuermann, S. J. Mabjeesh, and J. Miron. 2009. Effects of cooling dry cows under heat load conditions on mammary gland enzymatic activity, intake of food water, and performance during the dry period and after parturition. Livest. Sci. 124:189-195. https://doi.org/10.1016/j.livsci.2009.01.014.

Armstrong, D. V. 1994. Heat stress interaction with shade and cooling. J. Dairy Sci. 77:2044-2050.

Avendaño-Reyes, L., F. D. Alvarez-Valenzuela, A. Correa-Calderón, J S. Saucedo-Quintero, P. H. Robinson, and J. G. Fadel. 2006. Effect of cooling Holstein cows during the dry period on postpartum performance under heat stress conditions. Livest. Sci. 281:2535-2547. https://doi.org/10.1016/j.livsci.2006.06.009.

Beede, D. K., and R. J. Collier. 1986. Potential nutritional strategies for intensively managed cattle during thermal stress. J. Anim. Sci. 62:543-554.

Brandão, A. P., R. F. Cooke, F. N. Corrá, M. B. Piccolo, R. Gennari, T. Leiva, and J. L. Vasconcelos. 2016. Physiologic, health, and production responses of dairy cows supplemented with an immunomodulatory feed ingredient during the transition period. J. Dairy Sci. 99:5562-5572. https://doi.org/10.3168/jds.2015-10621.

Brown, D. E., P. C. Harrison, F. C. Hinds, J. A. Lewis, and M. H. Wallace. 1977. Heat stress effects on fetal development during late gestation in the ewe. J. Anim. Sci. 44:442-446.

Capuco, A. V., S. E. Ellis, S. A. Hale, E. Long, R. A. Erdman, X. Zhao, and M. J. Paape. 2003. Lactation persistency: Insights from mammary cell proliferation studies. J. Anim. Sci. 81:18-31.

Collier, R. J., G. E. Dahl, and M. J. Vanbaale. 2006. Major advances associated with environmental effects on dairy cattle. J. Dairy Sci. 89:1244-1253. https://doi.org/10.3168/jds.S0022-0302(06)721932 .

Collier, R. J., S. G. Doelger, H. H. Head, W. W. Thatcher, and C. J. Wilcox. 1982. Effects of heat stress during pregnancy on maternal hormone concentrations, calf birth weight and postpartum milk yield of Holstein cows. J. Anim. Sci. 54:309-319.

Dikmen, S., E. Alava, E. Pontes, J. M. Fear, B. Y. Dikmen, T. A Olson, and P. J. Hansen. 2008. Differences in thermoregulatory ability between slick-haired and wild-type lactating Holstein cows in response to acute heat stress. J. Dairy Sci. 91:3395-3402.

Dikmen, S., and P. J. Hansen. 2009. Is the temperature-humidity index the best indicator of heat stress in lactating dairy cows in a subtropical environment? J. Dairy Sci. 92:109-116.

do Amaral, B. C., E. E. Connor, S. Tao, M. J. Hayen, J. W. Bubolz and G. E. Dahl. 2009. Heat-stress abatement during the dry period: Does cooling improve transition into lactation? J. Dairy Sci. 92:5988-5999. https://doi.org/10.3168/jds.2009-2343.

do Amaral, B. C., E. E. Connor, S. Tao, M. J. Hayen, J. W. Bubolz, and G. E. Dahl. 2011. Heat stress abatement during the dry period influences metabolic gene expression and improves immune status in the transition period of dairy cows. J. Dairy Sci. 94:86-96.

Hall, L. W., F. A. Rivera, F. Villar, J. D. Chapman, N. M. Long, and R. J. Collier. 2014. Evaluation of OmniGen-AF in lactating heat stressed Holstein cows. Page 16 in 25th Annual Florida Ruminant Nutrition Symposium. Accessed Oct. 15, 2015. http://dairy.ifas. ufl.edu/rns/2014/collier.pdf.

Kaniyamattam, K., and A. De Vries. 2014. Agreement between milk fat, protein and lactose observations collected from the Dairy Herd Improvement Association (DHIA) and a real-time milk analyzer. J. Dairy Sci. 97:2896-2908. https://doi.org/10.3168/jds.2013-7690.
Nace, E. L., S. C. Nickerson, F. M. Kautz, S. Breidling, D. Wochele, L. O. Ely, and D. J. Hurley. 2014. Modulation of innate immune function and phenotype in bred dairy heifers during the periparturient period induced by feeding an immunostimulant for 60 days prior to delivery. Vet. Immunol. Immunopathol. 161:240-250.

NRC. 2001. Nutrient Requirements of Dairy Cattle. 7 th rev. ed. Natl. Acad. Sci., Washington, DC.

Renaudeau, D., A. Collin, S. Yahav, V. deBasilio, J. L. Gourdine, and R. L. Collier. 2012. Adaptation to hot climate and strategies to alleviate heat stress in livestock production. Animal 6:707-728.

Seigneuric, R., H. Mjahed, J. Gobbo, A. Joly, K. Berthenet, S. Shirley, and C. Garrido. 2011. Heat shock proteins as danger signals for cancer detection. Front. Oncol. https://doi.org/10.3389/ fonc.2011.00037.

Sobolewska, A., M. Gajewska, J. Zarzynska, B. Gajkowska, and T. Motyl. 2009. IGF-I, EGF, and sex steroids regulate autophagy in bovine mammary epithelial cells via the mTOR pathway. Eur. J. Cell Biol. 88:117-130. https://doi.org/10.1016/j.ejcb.2008.09.004.

Sorensen, M. T., J. V. N. Ørgaard, P. K. Theil, M. Vestergaard, and K. Sejrsen. 2006. Cell turnover and activity in mammary tissue during lactation and dry period in dairy cows. J. Dairy Sci. 89:4632-4639

St-Pierre, N. R., B. Cobanov, and G. Schnitkey. 2003. Economic losses from heat stress by US livestock industries. J. Dairy Sci 86(E.Suppl.):E52-E77. https://doi.org/10.3168/jds.S00220302(03)74040-5.

Tao, S., J. W. Bubolz, B. C. do Amaral, I. M. Thompson, M. J. Hayen, S. E. Johnson, and G. E. Dahl. 2011. Effect of heat stress during the dry period on mammary gland development. J. Dairy Sci. 94:5976-5986. https://doi.org/10.3168/jds.2011-4329.

Tao, S., and G. E. Dahl. 2013. Invited review: Heat stress effects during late gestation on dry cows and their calves. J. Dairy Sci 96:4079-4093. https://doi.org/10.3168/jds.2012-6278.

Tao, S., A. P. A. Monteiro, I. M. Thompson, M. J. Hayen, and G. E. Dahl. 2012a. Effect of late-gestation maternal heat stress on growth and immune function of dairy calves. J. Dairy Sci. 95:71287136

Tao, S., I. M. Thompson, A. P. A. Monteiro, M. J. Hayen, L. J. Young, and G. E. Dahl. 2012b. Effect of cooling heat-stressed dairy cows during the dry period on insulin response. J. Dairy Sci. 95:50355046. https://doi.org/10.3168/jds.2012-5405.

Wang, Y., S. B. Puntenney, J. L. Burton, and N. E. Forsberg. 2007. Ability of a commercial feed additive to modulate expression of innate immunity in sheep immunosuppressed with dexamethasone. Animal 1:945-951.

West, J. W. 2003. Effects of heat-stress on production in dairy cattle. J. Dairy Sci. 86:2131-2144.

Wilde, C. J., V. P. C. Addey, P. Li, and D. G. Fernig. 1997. Programmed cell death in bovine mammary tissue during lactation and involution. Exp. Physiol. 82:943-953.

Wohlgemuth, S. E., Y. Ramirez-Lee, S. Tao, A. P. A. Monteiro, B. M. Ahmed, and G. E. Dahl. 2016. Short communication: Effect of heat stress on markers of autophagy in the mammary gland during the dry period. J. Dairy Sci. 99:4875-4880. https://doi. org/10.3168/jds.2015-10649.

Zarzyńska, J., B. Gajkowska, U. Wojewodzka, E. Dymnicki, and T. Motyl. 2007. Apoptosis and autophagy in involuting bovine mammary gland is accompanied by up-regulation of TGF-beta (1) and suppression of somatotropic pathway. Pol. J. Vet. Sci. 10:1-9.

Zimbelman, R. B., R. P. Rhoads, M. L. Rhoads, G. C. Duff, L. H. Baumgard, and R. J. Collier. 2009. A re-evaluation of the impact of temperature humidity index (THI) and black globe humidity index (BGHI) on milk production in high producing dairy cows. Pages 158-168 in Proc. Southwest Nutr. Man. Conf., Tempe, AZ. Univ. Arizona, Tucson. 